\title{
Implementasi Kursus Calon Pengantin Berbasis Web Dalam Mengurangi Tingkat Penceraian
}

\author{
Slamet Widodo ${ }^{1}$, Herlambang Brawijaya ${ }^{1}$, Samudi $^{2}$ \\ ${ }^{1}$ Teknik dan Informatika, Sistem Informasi (D3), Universitas Bina Sarana Informatika, Jakarta, Indonesia \\ ${ }^{2}$ Prodi Sistem Informasi, STMIK Nusa Mandiri, Jakarta, Indonesia \\ Email: ${ }^{1}$ slamet.smd@ @si.ac.id, ${ }^{2}$ herlambang.braw@ gmail.com, ${ }^{3}$ samudi.net@ gmail.com \\ Email Penulis Korespondensi: slamet.smd@bsi.ac.id
}

\begin{abstract}
Abstrak-Pernikahan adalah ikatan lahir batin antara seorang laki-laki dan seorang perempuan untuk membentuk rumah tangga atau keluarga yang bahagia dan kekal berdasarkan Ketuhanan Yang Maha Esa. Meskipun demikian, banyak perceraian tetap terjadi di kalangan masyarakat saat ini. Suscatin merupakan sebuah solusi yang diberikan Pemerintah untuk mengatasi perceraian yang semakin tinggi setiap tahunnya. Namun masih terdapat kendala dalam penyelenggaraan Suscatin. Penyelenggaraan Suscatin masih dilakukan secara manual, dimana untuk melakukan ujian calon pengantin menulis di selembar kertas. Selain itu pelaksanaannya pun dilakukan pada hari efektif, sehingga calon pengantin tidak dapat hadir. Untuk itu penelitian ini dilakukan untuk merancang sebuah sistem pembelajaran berbasis web yang dapat memudahkan pihak Kantor Urusan Agama maupun calon pengantin. Sehingga materi-materi tentang pernikahan dapat dipelajari tanpa ada kendala baik dari segi waktu dan tempat pelaksanaan. Hal ini diharapkan dapat mengantisipasi terjadinya perselisihan dan perceraian maupun kekerasan dalam keluarga agar tercipta keluarga sakinah, mawaddah, dan rahmah.
\end{abstract}

Kata Kunci: Pernikahan, Suscatin, Kursus, Calon Pengantin, Website

Abstract-Marriage is a spiritual bond between a man and a woman to form a happy and eternal home or family based on the Godhead. Nevertheless, many divorces still occur in the community today. Suscatin is a solution provided by the Government to overcome divorce which is getting higher every year. But there are still obstacles in the organization of Suscatin. The Suscatin implementation is still done manually, where to conduct the exam the bride and groom write on a piece of paper. In addition, the implementation was carried out on the effective day, so the bride and groom could not attend. For this reason, this research was conducted to design a web-based learning system that can facilitate the Office of Religious Affairs and prospective brides. So that the material about marriage can be studied without any obstacles both in terms of time and place of implementation. It is expected to be able to anticipate disputes and divorce as well as violence in the family in order to create a sakinah, mawaddah, and rahmah family.

Keywords: Marriage, Suscatin, Courses, Prospective Brides, Websites

\section{PENDAHULUAN}

Pernikahan adalah ikatan lahir batin antara seorang laki-laki dan seorang perempuan untuk membentuk rumah tangga atau keluarga yang bahagia dan kekal berdasarkan Ketuhanan Yang Maha Esa, hal ini diatur dalam undang-undang nomor 1 tahun 1974. Tidak hanya itu saja perkawianan merupakan sunnatullah yang berlaku pada pada semua makhluk Allah, bak manusia, hewan, maupun tumbuh-tumbuhan [1]. Keinginan untuk menikah adalah fitrah manusia. Baik bagi laki-laki maupun perempuan, keinginan untuk menikah sudah mulai berputik ketika usia manusia telah beranjak remaja [2].

Namun tidak selamanya pernikahan ideal tersebut dapat berjalan dengan baik tatkala dihadapkan pada permasalahan yang pelik. Bagi sebagian pasangan akan mencoba bertahan dan menyelesaikan masalah, namun bagi sebagian pasangan lainnya memilih untuk berpisah dengan cara perceraian. Berdasarkan jumlah talak dan cerai yang dirilis oleh Badan Pusat Statistik menunjukkan adanya peningkatan yang cukup signifikan dari tahun ketahun [3]. Tidak hanya itu saja karena tidak setiap wanita melakukan persiapan medis menjelang perkawinanya. Padahal tak sedikit manfaat yang dapat dipetik dari kesiapan medis wanita sebelum memasuki jenjang pernikahan [4]. Untuk mengurangi pengetahuan bagi calon pengantin selama ini pendekatan yang dilakukan adalah pemberian informasi oleh petugas kesehatan [5].

Kasus penceraian sudah menjadi fenomena yang banyak terjadi pada saat sekrang ini [6]. Melihat jumlah talak dan cerai yang semakin meningkat, Pemerintah memberikan perhatian khusus untuk menekan angka perceraian yang terjadi di kalangan masyarakat Indonesia [7]. Tentang Penyelenggaraan Kursus Pra Nikah. Adapun institusi yang berwenang dalam melangsungkan Suscatin adalah Kantor Urusan Agama (KUA) atau BP4. Secara teoretis, cakupan materi suscatin yang diselenggarakan oleh KUA sudah cukup representatif, yakni meliputi tatacara dan prosedur perkawinan, pengetahuan agama, peraturan perundangan di bidang perkawinan dan keluarga, hak dan kewajiban suami istri, kesehatan reproduksi perempuan, manajemen keluarga, dan psikologi perkawinan dan keluarga [8].

Semua materi yang ditawarkan dalam kursus pra nikah ini narasumbernya diundang dari berbagai unsur sesuai dengan kompetensi dan keahliannya masing masing diantaranya dari KEMENAG [9]. Tidak dapat dipungkiri bahwa pelaksanaan Suscatin selama dua hari pada hari efektif menemui kendala, terutama dari segi peserta suscatin yang tidak dapat hadir karena terbentur jadwal kerja maupun keperluan lain yang tidak bisa ditinggalkan. Hal tersebut menyebabkan materi dan pengujian sejauh mana pengetahuan calon pengantin dalam memahami hakikat pernikahan menjadi kurang tersampaikan dengan baik. Padahal untuk mendapatkan sertifikat 
yang menjadi syarat kelengkapan pencatatan pernikahan, calon pengantin diharuskan mengikuti Suscatin terlebih dahulu.

Kursus Calon Pengantin adalah pemberian bekal pengetahuan, pemahaman dan keterampilan yang difokuskan kepada calon pengantin yang akan melangsungkan pernikahan dalam waktu dekat [10]. Kelas calon pengantin (catin) merupakan salahsatu usaha dan kepedulian pemerintah untuk mengurangi angka perceraian. Tujuannya adalah untuk meningkatkan keharmonisan dalam rumah tangga sehingga mengurangi kemungkinan terjadinya perceraian [11]. Selama ini konseling yang diberikan kepaada catin oleh petugas pelayanan kesehatan masih menggunakan lembar balik atau leafleat [12].

Pada penelitian yang dilakukan Iskandar membahas tentang hal-hal yang berkaitan dengan Suscatin yang diberlakukan di Indonesia, Malaysia, Brunei dan Singapura. Menyimpulkan bahwa dalam pelaksanaan program Suscatin masih berjalan kurang efektif baik dari segi waktu maupun peserta [13] . Karena program Suscatin diberikan sekurang-kurangya 24 jam pelajaran dengan waktu tertentu selama 3 hari atau dibuat beberapa kali pertemuan dengan jumlah jam pelajaran yang sama. Hal ini membuat peserta Suscatin kerap kali tidak bisa hadir mengikuti program tersebut. Pengetahuan calon pengantin laki-laki yang memiliki pengetahuan kurang lebih besar daripada calon pengantin perempuan [14]. Berdasarkan pada latar belakang di atas, maka rumusan masalah pada penelitian ini adalah bagaimana merancang sebuah sistem pembelajaran yang memudahkan peserta Suscatin mempelajari materi-materi pernikahan, serta dapat melakukan ujian dimana saja agar lebih efektif dan efisien, sehingga pemahaman tentang berumah tangga bagi calon pasangan suami istri dapat tercapai dengan baik.

\section{METODE PENELITIAN}

Metode yang digunakan pada penelitian ini menggunakan metode pengembangan perangkat lunak secara sekuensial atau terurut [15] , dimulai dari analisis, desain, pengodean, pengujian, dan tahap pendukung. Dari lima langkah yang terdapat pada metode waterfall, penulis menggunakan tiga langkah dalam merancang sistem pembelajaran Suscatin, diantaranya:

1. Analisis kebutuhan perangkat lunak

Proses pengumpulan kebutuhan dilakukan secara intensif untuk mespesifikasikan kebutuhan sistem agar mendapat hasil yang tepat guna. Kebutuhan yang diperlukan dalam sistem pembelajaran Suscatin mencakup kebutuhan administrator akan akses penuh terhadap pengelolaan sistem pembelajaran, kebutuhan peserta dalam mengerjakan soal, dan kebutuhan Instruktur dalam merespon pembelajaran. Hasilnya berupa prototype sistem pembelajaran berorientasi objek berbasis web.

2. Desain

Desain perangkat lunak adalah proses multi langkah yang fokus pada desain pembuatan program perangkat lunak termasuk struktur data, arsitektur perangkat lunak, representasi antarmuka, dan prosedur pengodean. Tahap ini mentranslasi kebutuhan perangkat lunak dari tahap analisis kebutuhan ke representasi desain agar dapat diimplementasikan menjadi program pada tahap selanjutnya. Adapun tools system yang digunakan yaitu Entity Relational Diagram (ERD) dan Logical Record Structure (LRS).

3. Pembuatan kode program

Desain harus ditranslasikan ke dalam program perangkat lunak. Hasil dari tahap ini adalah program komputer sesuai dengan desain yang telah dibuat pada tahap desain. Database yang digunakan adalah MySQL, sementara pembuatan kode program menggunakan bahasa PHP.

Selanjutnya metode penelitian ini akan digambarkan dengan flowchart sebagai berikut :

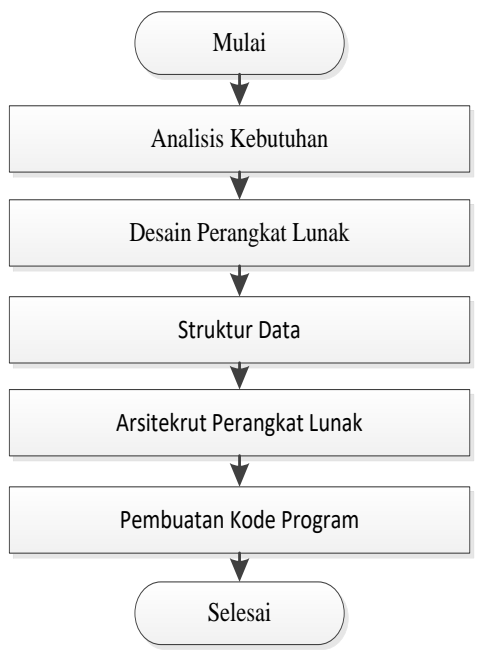

Gambar 1. FlowChart Penelitian 


\section{HASIL DAN PEMBAHASAN}

1. Analisis Kebutuhan

Dalam sistem pembelajaran Sucatin berbasis Web terdapat tiga pengguna yang dapat berinteraksi dalam lingkungan sister, yaitu : Administrator, Intsruktur, dan Calon Pengantin. Ketiga pengguna tersebut memiliki karakteristik interaksi dengan sistem yang berbeda-beda, seperti berikut:

A. Administrator

1. Mengelola kelas Suscatin

2. Mengelola data Calon Pengantin

3. Mengelola data Instruktur

4. Mengelola materi Suscatin

5. Mengelola soal pre test dan post test

B. Calon Pengantin

1. Mengerjakan pre test

2. Mengunduh materi Suscatin

3. Melakukan diskusi dengan Instruktur

4. Mengerjakan post test

5. Mengunduh e-sertifikat

C. Instruktur

Melakukan diskusi dengan Calon Pengantin sehingga proses kursus calon pengantin bias berjalan dengan baik.

\section{Desain Sistem}

A. Use Case SUCATIN

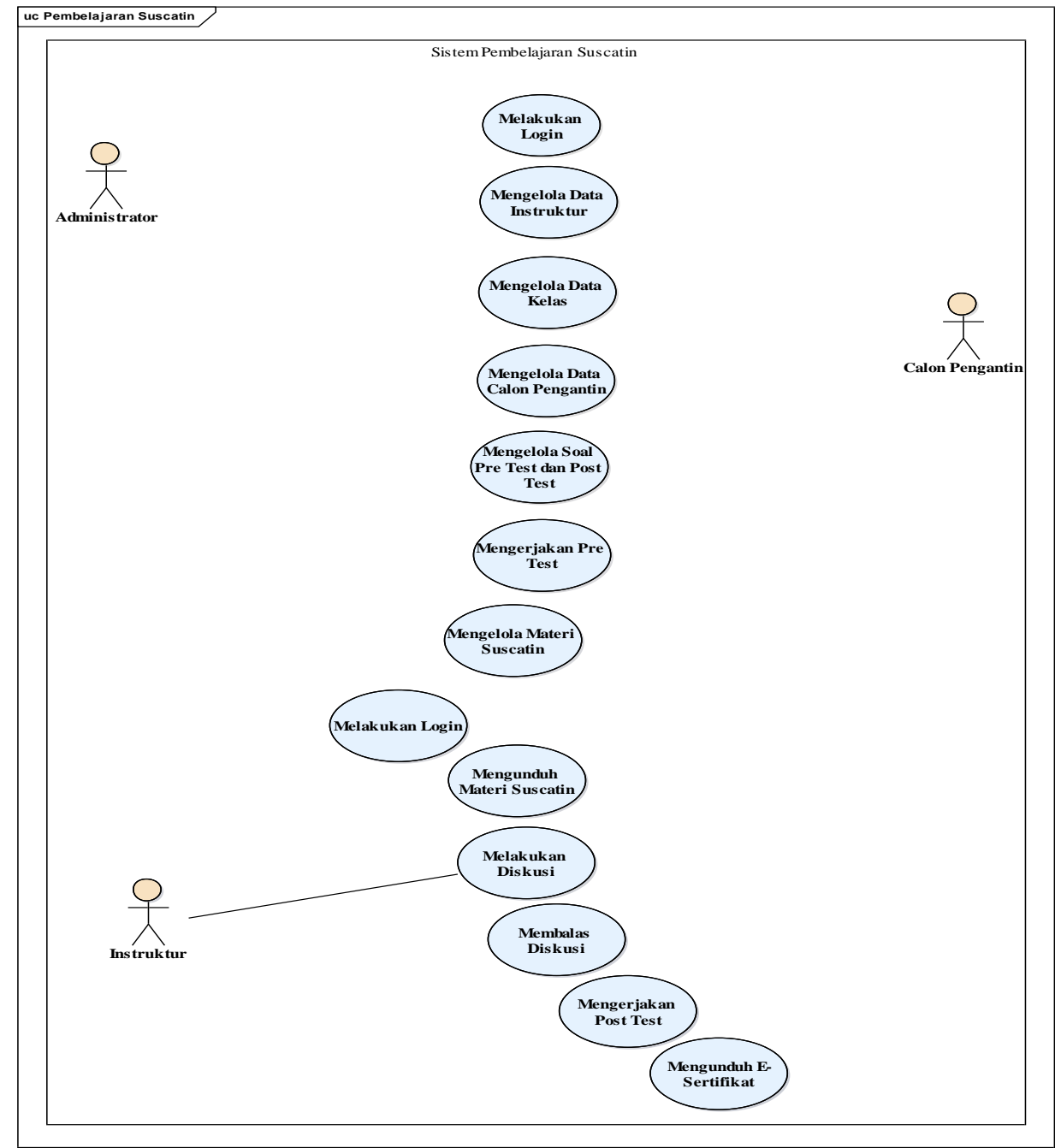

Gambar 2. Diagram Use Case SUCATIN

Untuk mengakses SUCATIN pengguna harus melakukan login terlebih dahulu dengan memasukkan username dan password. Jika sudah selesai menggunakan aplikasi, pengguna harus melakukan logout. 
JURNAL MEDIA INFORMATIKA BUDIDARMA

Volume 4, Nomor 3, Juli 2020, Page 676-682

ISSN 2614-5278 (media cetak), ISSN 2548-8368 (media online)

Available Online at https://ejurnal.stmik-budidarma.ac.id/index.php/mib

DOI 10.30865/mib.v4i3.2170

B. Diagram Activity Login

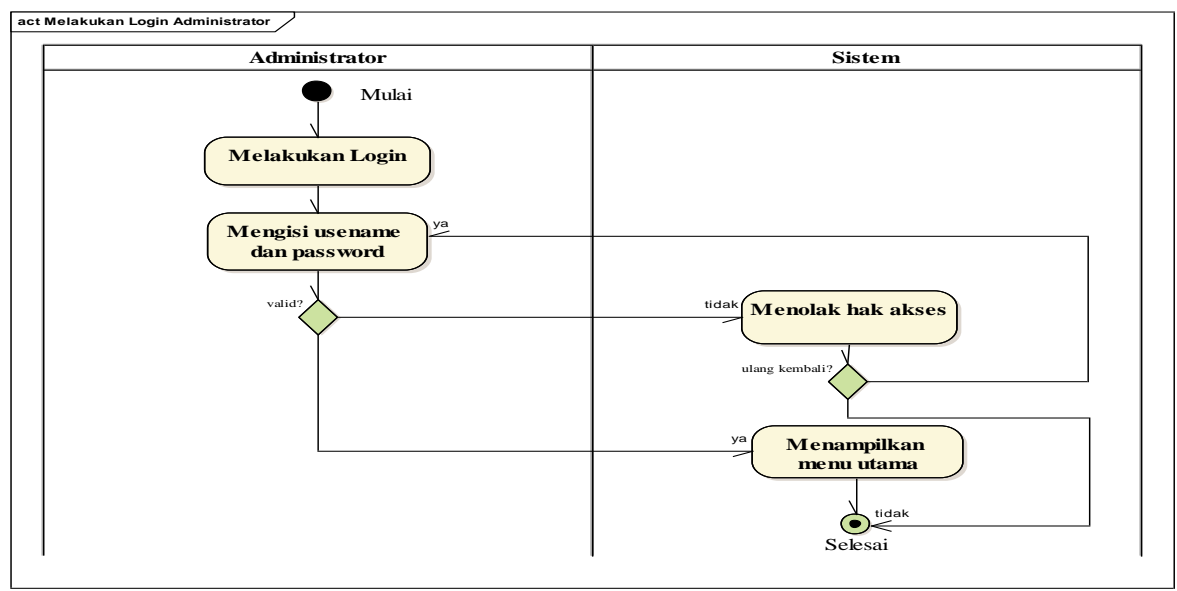

Gambar 3. Diagram Activity Login

C. Diagram Activity Mengerjakan Post Test

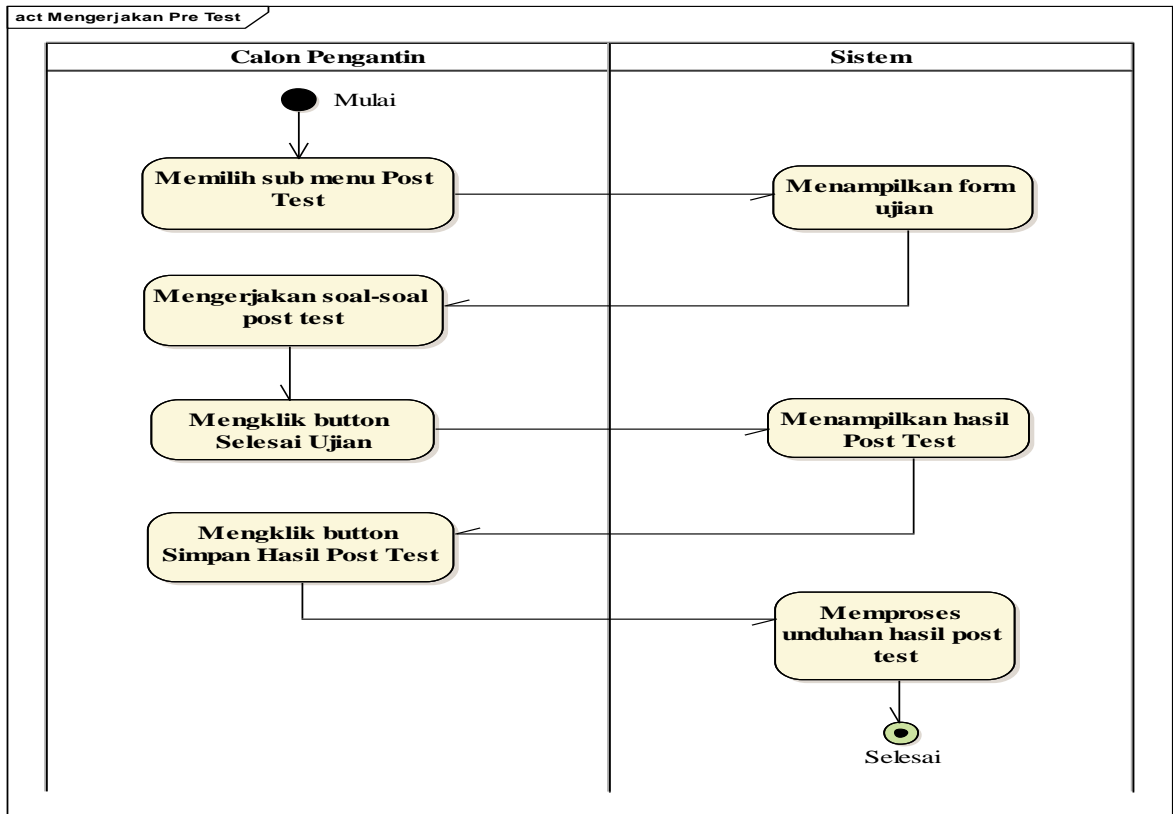

Gambar 4. Diagram Activity Mengerjakan Post Test

D. Diagram Activity Mengunduh Sertifikat

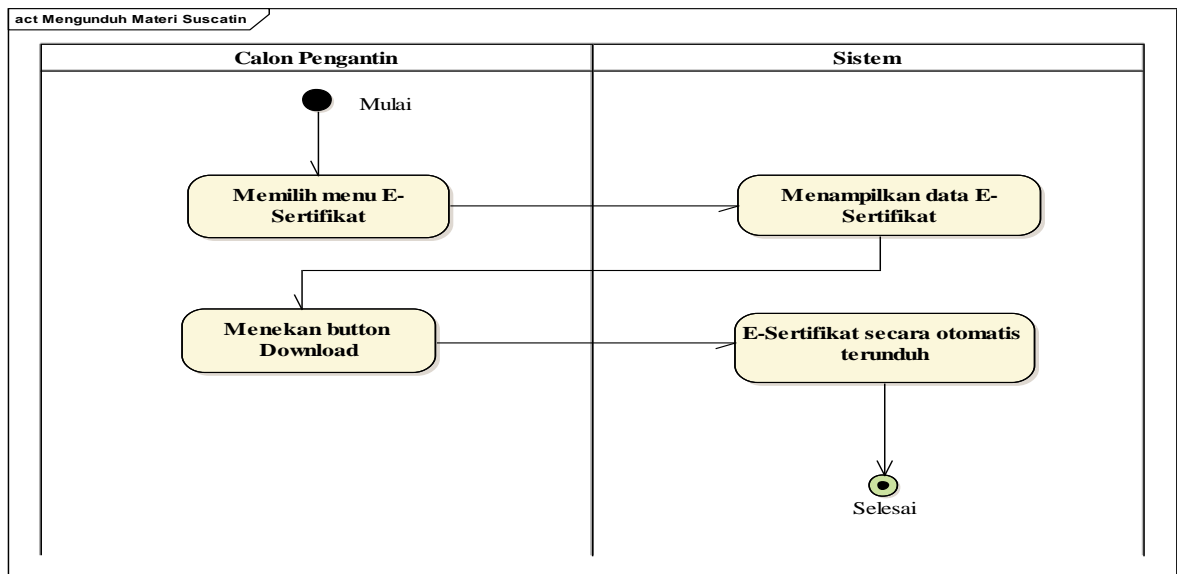

Gambar 5. Diagram Activity Mengunduh Sertifikat 


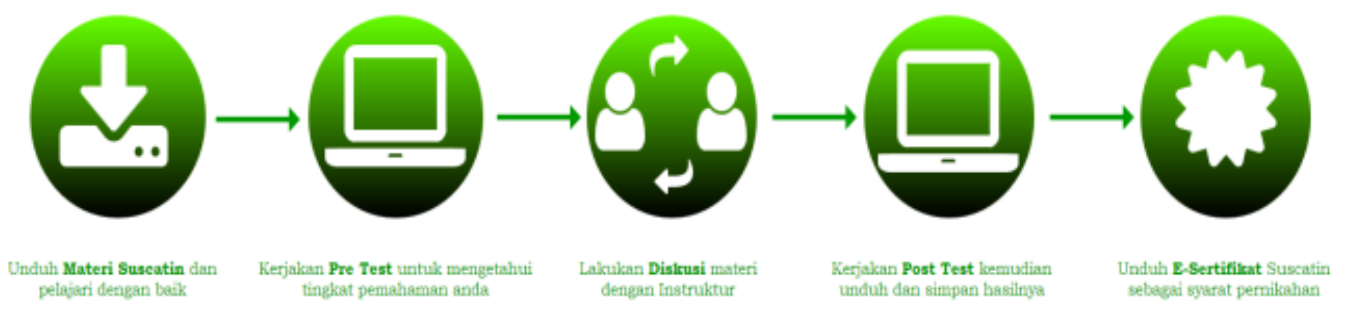

Gambar 6. Beranda SUCATIN

Pada interface diatas pengguna bias dapat mengunduh materi sucatin yang dapat dipelajarinya. Kemudian mengerjakan Pre Test untuk mengetahui tingkat pemahaman dari materi yang dipelajari. Pengguna juga dapat berdiskusi dengan instruktur jika sudah berdiskusi pengguna dapat melakukan Post Test untuk dikerjakan dan di simpan dan akan mengahasilkan E-Sertifikat Sucatin sebagai persyaratan pernikahan.

F. Interface Balas Diskusi SUCATIN

E-learning Suscatin Bernadu Diskusi Profil Catin Materi Suscatin E-Sertifikat Ujan v a Catin *
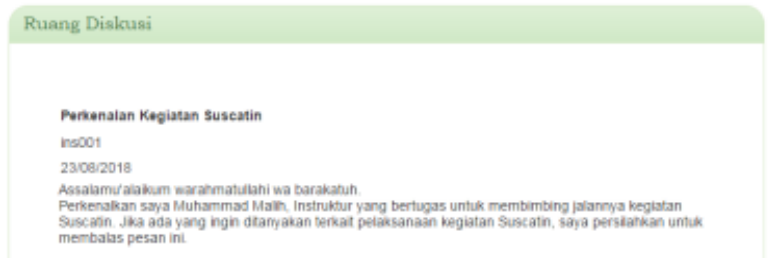

\section{Gambar 7. Diskusi SUCATIN}

Interface diatas untuk melakukan diskusi calon pengantin kepada instruktur agar setiap pertanyaan yang di miliki calon pengantin dapat di sampaikan secara langsung dan di jawab oleh instruktur pada proses Sucatin.

G. Interface Pre SUCATIN

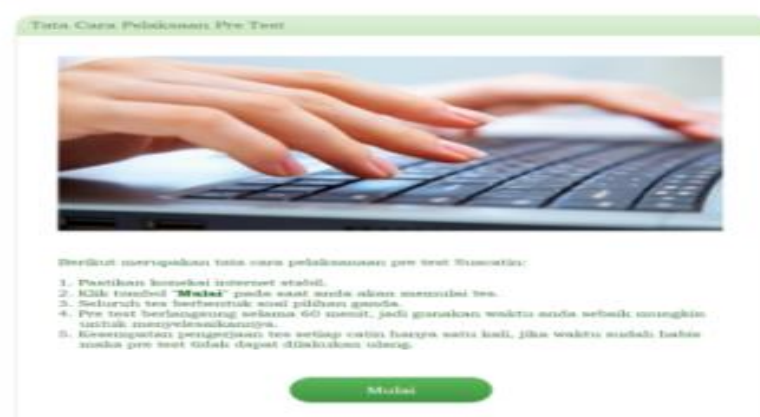

Gambar 8. Pre SUCATIN

Slamet Widodo, Copyright (C2020, MIB, Page 680 
ISSN 2614-5278 (media cetak), ISSN 2548-8368 (media online)

Available Online at https://ejurnal.stmik-budidarma.ac.id/index.php/mib DOI 10.30865/mib.v4i3.2170

Interface pre test sucatin yang dapat di kerjakan dengan pilihan ganda dan waktu pengerjaannya 60 menit, bagi calon pengantin dapat menggunakan waktu dengan sebaik baiknya selama proses pre test.

H. Interface Cetak Bukti Pre tes SUCATIN

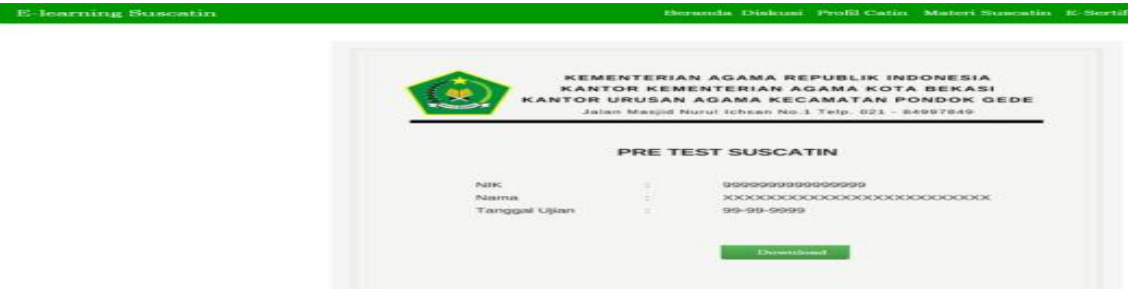

Gambar 9. Cetak Bukti Pre Test

Interface diatas adalah hasil yang akan didapat ketika sudah melakukan pre test pada Sucatin dengan menampilkan data sesuai dengan pengguna sucatin.

I. Interface Sertifikat SUCATIN

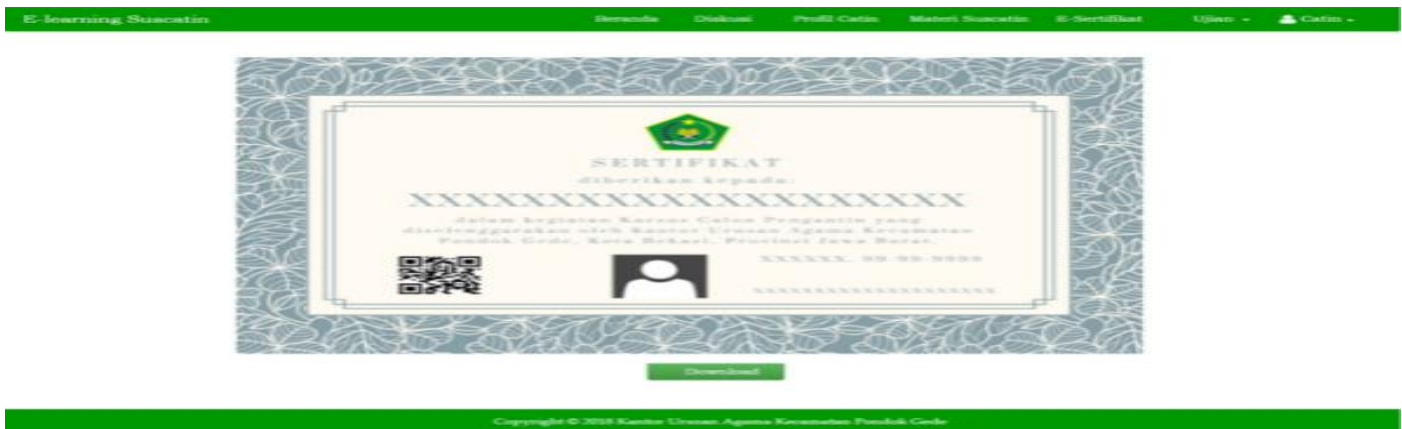

Gambar 10. Sertifikat SUCATIN

Interface diatas adalah sertifikat yang akan di dapat oleh calon pengantin sebagai salah satu syarat yang telah di kerjakan dari mengerjakan pre test sucatin untuk pernikahan.

\section{KESIMPULAN}

Berdasarkan penelitian di atas penulis bisa mengambil kesimpulan mengenai bahwa dengan Sistem pembelajaran Suscatin merupakan salah satu strategi dalam meningkatkan pengetahuan dan ketrampilan calon pengantin tentang berumah tangga. Kursus calon pengantin ini diharapkan dapat mengantisipasi terjadinya perselisihan dan perceraian maupun kekerasan dalam keluarga agar tercipta keluarga sakinah, mawaddah, dan rahmah. Dengan adanya sistem pembelajaran Suscatin berbasis web diharapkan akan mempermudah calon pengantin dalam mengakses seluruh kegiatan Suscatin, tanpa harus datang secara langsung ke KUA. Serta dapat memudahkan pengolahan data dan efisiensi waktu bagi pihak KUA.

\section{REFERENCES}

[1] L. Purnamasari and Iwannudin, "Kursus Calon Pengantin (SUSCATIN) Dalam Membina Keharmonisan Rumah Tangga Di Kecamatan Metro Timur," Mahkamah, vol. 3, no. 2, 2018.

[2] G. Timur, Panduan Calon Pengantin: Seri Panduan Hidup Mukmin. Giliran Timur Books, 2015.

[3] BPS, "Nikah, Talak dan Cerai, Serta Rujuk," 2015. [Online]. Available: www.bps.go.id/linkTableDinamis/view/id/893. [Accessed: 20-Aug-2004].

[4] H. Nadesul, Buku Sehat Calon Pengantin dan Keluarga Muda. Jakarta: Penerbit Buku Kompas, 2007.

[5] Suriah, Citrakesumasari, Awaluddin, and A. Yani, "Education For Prospective Brides On Nutritional Anemia And Chronic Energy In Parepare City,” Media Publ. Promosi Kesehat. Indones., vol. 1, no. 1, pp. 25-31, 2018.

[6] D. Susanti, Y. Rustam, and windra doni Alstri, "Pengaruh Pendidikan Kesehatan Pranikah Terhadap Pengetahuan Dan Sikap Calon Pengantin Di Lubuk Begalung Padang Tahun 2017,” vol. 13, no. 2, pp. 18-25, 2018.

[7] Dirjen Bimas Islam, Pedoman Penyelenggaraan Kursus Pra Nikah. 2013.

[8] U. Na'mah, "Pentingnya Peran Suscatin (Kursus Calon Pengantin) Dalam Membendung Laju Perceraian," YUDISIA J. Pemikir. Huk. Dan Huk. Islam, pp. 147-174, 2016.

[9] Z. Sesmiarni and Afrinaldi, "Model Pendidikan dan Pelatihan Calon Pengantin Berbasis Kearifan Lokal di Kota Pariaman," J. Educ. Stud., vol. 1, no. 1, pp. 35-44, 2016.

[10] M. Al Faruq, "Efektifitas SUSCATIN dalam Membentuk Keluarga yang Sakinah Mawaddah Wa Rahmah,” J. ElFaqih, pp. 112-127, 2019.

[11] R. Amalia and P. Siswantara, "Efektivitas Penyuluhan Kesehatan Reproduksi Pada Calon Pengantin Di Puskesmas Pucang Sewu Surabaya," J. Biometrika dan Kependud., vol. 7, no. 1, pp. 29-38, 2018. 
JURNAL MEDIA INFORMATIKA BUDIDARMA

Volume 4, Nomor 3, Juli 2020, Page 676-682

ISSN 2614-5278 (media cetak), ISSN 2548-8368 (media online)

Available Online at https://ejurnal.stmik-budidarma.ac.id/index.php/mib

DOI 10.30865/mib.v4i3.2170

[12] A. Ratnasari, "Perancangan Aplikasi Edukasi Calon Pengantin untuk Peningkatan Pengetahuan Pra Kehamilan Berbasis Android," Semin. Nas. Inform. Medis, pp. 51-56, 2018.

[13] Z. Iskandar, Peran Kursus Pra Nikah Dalam Mempersiapkan Pasangan Suami-Istri Menuju Keluarga Sakinah. AlAhwal, 2017.

[14] D. Nurlaela, P. Sari, N. Martini, M. Wijaya, and R. T. Dewi, "Efektivitas Pendidikan Kesehatan Melalui Media Kartu Cinta Anak Tentang 1000 Hari Pertama Kehidupan dalam Meningkatkan Pengetahuan Pasangan Calon Pengantin di KUA Kecamatan Jatinangor,” J. Kwsehatan Vokasional, vol. 3, no. 2, pp. 62-68, 2018.

[15] M. Sukamto, R. A., \& Shalahudin, Rekayasa Perangkat Lunak Terstruktur dan Berorientasi Objek. Informatika Bandung, 2015 